Proof to: Shunji Kinoshita

Department of Chemistry

Konan University

Okamoto 8-9-1, Higashinada-ku

Kobe 658-8501, Japan

E-mail: dn122002@center.konan-u.ac.jp

tel: $+81-78-435-2563$

fax: $+81-78-435-2539$

\title{
All-Solid-State Lithium Battery with Sulfur/Carbon Composites as Positive Electrode Materials
}

Shunji Kinoshita, Kazuya Okuda, Nobuya Machida, Muneyuki Naito,

Toshihiko Sigematsu

Department of Chemistry, Konan University, 8-9-1 Okamoto, Higashinada-ku Kobe 658-8501, Japan

E-mail: $\underline{\text { dn122002@center.konan-u.ac.jp }}$ 


\begin{abstract}
Sulfur-carbon composites were investigated as positive electrode materials for all-solid-state lithium ion batteries with an inorganic solid electrolyte (amorphous $\mathrm{Li}_{3} \mathrm{PS}_{4}$ ). The elemental sulfur was mixed with Vapor-Grown Carbon Fiber (VGCF) and with the solid electrolyte (amorphous $\mathrm{Li}_{3} \mathrm{PS}_{4}$ ) by using high-energy ball-milling process. The obtained sulfur-VGVF-solid electrolyte composite was used as positive electrode materials of the all-solid-state battery. The composite showed good electrochemical properties as positive electrode materials. The capacity that was calculated on the base of the weight of sulfur was about $1300 \mathrm{mAhg}^{-1}$ at room temperature, when the all-solid-state battery was discharged and charged in the voltage range of 0.9 to $2.6 \mathrm{~V}$ at a constant current density of $0.1 \mathrm{mAcm}^{-2}$. The battery kept the capacity more than $1200 \mathrm{mAhg}^{-1}$ even after 50 discharge-charge cycles.
\end{abstract}

Keyword: sulfur, positive electrode materials, Li/S cell, Lithium battery, All-solid-state battery, . 


\section{Introduction}

Rechargeable lithium ion batteries are widely used as a power source of portable electronic devices. Especially large-scale power sources for electric vehicles require high energy density compared with the conventional lithium ion batteries [1] Elemental sulfur is one of the very attractive as positive electrode materials for high-specific-energy rechargeable lithium batteries, because of its high theoretical specific capacity of $1675 \mathrm{mAhg}^{-1}$ [1-11]. However, sulfur does not work successfully as reversible positive electrode materials in the lithium batteries with electrolyte solutions. The capacity of the $\mathrm{Li} / \mathrm{S}$ battery using electrolyte solution rapidly fades away on cycling. The capacity fading is attributed to the facts that the reduction of sulfur produces several lithium poly-sulfides in the batteries and the lithium poly-sulfides can dissolve into the electrolyte solutions. The dissolved poly-sulfide ions diffuse to the anode and are reduced there in charging process. This poly-sulfide ion shuttle mechanism prevents the $\mathrm{Li} / \mathrm{S}$ battery from working with good charge-discharge cycle performance [1-8].

An all-solid-state lithium battery with inorganic solid electrolytes, in which only $\mathrm{Li}^{+}$ions can migrate, is expected as an excellent device form that can make elemental sulfur work as electrode materials, because the lithium poly-sulfides that have been produced during the discharge process of the sulfur electrode do not dissolve in the solid electrolytes. The poly-sulfide ions could not diffuse through the solid electrolyte and also could not reach to the anode. The poly-sulfide-ion shuttle mechanism, consequently, does not arise in the all-solid-state battery $[12,13]$. From those view points, some $\mathrm{Li} / \mathrm{S}$ batteries using inorganic solid electrolytes have been examined [12-16]. Recently, we have reported that a mixture of elemental sulfur and copper is 
able to work as reversible cathode materials for all-solid-state battery with inorganic solid electrolytes and that the sulfur in the mixture shows a high reversible charge-discharge capacity larger than $1000 \mathrm{mAhg}^{-1}$. In this cell, copper atoms work as catalyst in order to change the sulfur into copper sulfide $(\mathrm{CuS})$ and the $\mathrm{CuS}$ works as active materials in the battery $[12,13]$. However, the specific gravities of the copper and/or copper sulfide are higher than that of elemental sulfur. Thus, the specific energy density of a Li/S battery with the mixture of sulfur and copper becomes low. On the other hand, specific gravity of carbon is smaller than that of copper metal and/or copper sulfide. Hence, the $\mathrm{Li} / \mathrm{S}$ battery using sulfur-carbon (S/C) composite electrode is expected to have a high specific energy density.

There are some works on the composite electrodes of sulfur and carbon and those works have reported that the composite shows good charge-discharge performance $[17$, 18]. Kobayashi et al. have reported that the composite of sulfur and carbon prepared by gas-phase mixing shows good performance as cathode materials for all-solid-state battery [19]. The composite materials show the reversible capacity $420 \mathrm{mAhg}^{-1}$ on the base of sulfur weight at room temperature. Nagao et al. have also reported that sulfur-acetylene black composites show excellent performance as cathode materials for all-solid-state battery [20]. The solid-state cell with the sulfur-acetylene black composites that has been prepared by the ball-milling process shows high reversible capacity over $1400 \mathrm{mAhg}^{-1}$ on the base of sulfur weight at room temperature.

The specific capacities reported those previous works are quite different. The specific capacity of sulfur reported by Nagao et al. is about 3 times larger than that reported by Kobayashi et al. The disagreement suggests that the performance of the sulfur in all-solid-state cells strongly depends on the preparation process of the S/C 
composites.

Nagao et al. also reported the electrochemical properties of the sulfur-acetylene black composites that were prepared by two different procedures; one was a mortar grinding process and the other was a planetary ball-milling process. The sulfur-acetylene black composite was prepared by the mortar grinding showed poor reversible capacity less than $100 \mathrm{mAhg}^{-1}$. On the other hand, the sulfur-acetylene black composite was prepared by using planetary ball-milling showed large reversible capacities about $1400 \mathrm{mAhg}^{-1}$. Those results suggested that the preparation processes of sulfur-acetylene black composite electrode were a key step to make the composites work as high performance positive electrodes. However, the preparation conditions of the composite electrodes have not been discussed yet.

In those previous works, acetylene black was used as carbon materials to provide electrical conductivity to those sulfur-carbon composites. The acetylene black has small particle shapes with 30 to $50 \mathrm{~nm}$ in diameter. On the other hand, there is another type of carbon materials, Vapor Grown Carbon Fiber (VGCF) that has short-fiber shapes with $15 \mu \mathrm{m}$ length and $15 \mathrm{~nm}$ in diameter.

We suppose that the carbon materials (VGCF) with short-fiber shapes should have advantages in providing electrical conductivity to the sulfur-carbon composites for all-solid-state lithium ion batteries. In this study, we try to prepare the sulfur-VGCF composites and to optimize the preparation conditions of the sulfur-VGCF composite electrode by using high-energy ball-milling.

\section{Experimental}

The sulfur-VGCF composites were prepared by two-step ball-milling process 
(Step-A and Step-B). Fig. 1 shows a schematic diagram of the two-step ball-milling process to prepare the sulfur-VGCF composites as positive electrode materials for all-solid-state batteries with the amorphous $\mathrm{Li}_{3} \mathrm{PS}_{4}$ solid electrolytes. The a-Li $\mathrm{PS}_{4}$ was also prepared from the raw materials $\mathrm{Li}_{2} \mathrm{~S}$ (Nippon Chemical Industrial, 99\%) and $\mathrm{P}_{2} \mathrm{~S}_{5}$ (Aldrich, 99\%) by a high-energy ball-milling process that was reported elsewhere [21-24].

The sulfur-carbon composites were prepared from sulfur (Wako chemicals, 99\%), VGCF (Showa Denko) and amorphous $\mathrm{Li}_{3} \mathrm{PS}_{4}$. The first step (Step-A) of the composite preparation was the mixing process of only two components, sulfur and VGCF, in order to provide electronic conductivity to the composites. In the Step-A, the sulfur $(75$ wt. \%) and VGCF $(25$ wt. \%) were placed into a stainless steel vial (SUS-316) with tetragonal zirconia ball ( 7 balls of $10 \mathrm{~mm}$ diameter) and the vial was sealed with an O-ring. The total mass of the starting materials was $1.0 \mathrm{~g}$. A high-energy ball-milling apparatus (Fritch P-7) was used for this preparation step. The ball-milling rotation speed was $380 \mathrm{rpm}$ and the milling time was changed in the range of 3 to $70 \mathrm{~h}$. The obtained samples in Step-A were called precursors in this study.

The next step (Step-B) was the mixing process of the solid electrolyte, a- $\mathrm{Li}_{3} \mathrm{PS}_{4}$ (SE), and the precursors obtained in Step-A. The mixture of the solid electrolyte (60 wt. \%) and the precursors (40 wt. \%) was placed in a vial (SUS-316) with zirconia ball (7 balls of $10 \mathrm{~mm}$ diameter) and the vial was sealed with an O-ring. The total mass of the mixture was $1.0 \mathrm{~g}$, and the ball-milling rotation speed was $380 \mathrm{rpm}$. The milling times was varied in the range of 3 to $40 \mathrm{~h}$ in order to optimize the preparation conditions of the composites. The obtained composites consist of sulfur, VGCF and 
the solid electrolyte $\left(\mathrm{a}-\mathrm{Li}_{3} \mathrm{PS}_{4}\right)$ in the weight ratio of $30: 10: 60$.

Two series of the composites were prepared by the two-step ball-milling process. The composite-A was prepared under the conditions as follows: the various milling times of Step-A in the range of 3 to $70 \mathrm{~h}$ and the constant milling time of $5 \mathrm{~h}$ in Step-B. On the other hand, the composite-B was prepared under the other conditions: the constant milling time of $10 \mathrm{~h}$ in Step-A and the various milling times in the range of 3 to $40 \mathrm{~h}$ in Step-B. The obtained samples were characterized by an X-ray powder diffraction $(\mathrm{XRD})$ measurement using a diffractometer with $\mathrm{Cu}-\mathrm{K} \alpha$ radiation. For the measurement the samples were sealed in an airtight container with beryllium windows and the container was mounted on the X-ray diffractometer (Rigaku, Multi Flex). The morphology of the obtained samples was evaluated by scanning electron microscope (JEOL, JSM-6340F).

The electrochemical properties of the obtained two series of the sulfur-VGCF-solid electrolyte composites (composite-A and -B) were investigated by using an all-solid-state cell. The solid-state test cell was constructed from three layers: one is the cathode layer that is composed of the sulfur-VGCF-solid electrolyte (SE) composite, another part is the solid electrolyte layer that is consisted of only the solid electrolyte (amorphous $\mathrm{Li}_{3} \mathrm{PS}_{4}$ ), and the other part is the anode layer that is consisted of a meta-stable $\mathrm{Li}_{4.4} \mathrm{Si}$ alloy. The meta-stable $\mathrm{Li}_{4.4} \mathrm{Si}$ alloy was also prepared by using a high-energy ball-milling process $[25,26]$. The cell was prepared by successively pressing the sulfur-VGCF-SE composite powders (composite-A or -B), amorphous $\mathrm{Li}_{3} \mathrm{PS}_{4}$ solid electrolytes and $\mathrm{Li}_{4.4} \mathrm{Si}$ alloy into a pellet of $10 \mathrm{~mm}$ in diameter at $380 \mathrm{MPa}$. The loadings of the sulfur-VGCF-SE composite and $\mathrm{Li}_{4.4} \mathrm{Si}$ alloy in the cell were $14.3 \mathrm{mg} \mathrm{cm}^{-2}$ and $19.1 \mathrm{mg} \mathrm{cm}^{-2}$, respectively. The solid-state cell was cycled 
in the voltage range of 0.9 to $2.6 \mathrm{~V}$ at a constant current density of $0.1 \mathrm{mAcm}^{-2}$ $\left(24 \mathrm{mAg}^{-1}\right)$ at $25^{\circ} \mathrm{C}$ by use of a battery tester (BTS-2004H, Nagano Co Ltd.).

\section{Results and Discussion}

\section{1. Preparation of $S / C$ composites and their morphology}

Fig. 2 shows XRD patterns of the precursors obtained in Step-A with various milling times of 5 to $70 \mathrm{~h}$. The precursors show the diffraction peaks attributed to crystalline sulfur. The intensity of the diffraction lines decreases with an increase in the milling time. In addition, the widths of those diffraction lines become broader with increasing the milling time. The results suggest that the crystallinty of the sulfur in the precursor should be degraded and the crystallite size of sulfur should be reduced in the milling process (Step-A). We checked the temperature of the milling vials immediately after the milling. The temperature of the vials after milling was in the range of 30 to $40{ }^{\circ} \mathrm{C}$. Then, the temperature did not increase so high during the milling process.

The morphology of the precursors obtained by the Step-A is investigated by SEM observation. The SEM images of the precursors prepared with the various milling times of Step-A are shown in Fig. 3. The SEM image of the VGCF is also shown in the figure for comparison. The VGCF has fiber morphology with an aspect ratio about 100 (diameter: $150 \mathrm{~nm}$, length: c. a. $15 \mu \mathrm{m}$ ) as shown in Fig. 3 (a). In the precursor obtained by $5 \mathrm{~h}$ ball-milling in Step-A, the VGCF fibers stick into the sulfur particles and the composite has a burr-like shape as shown in Fig. 3 (b). The particle size of the precursor ball-milled for $5 \mathrm{~h}$ is about 5 to $15 \mu \mathrm{m}$ and the length of the ball-milled VGCF becomes somewhat shorter than the raw VGCF. When the mixture 
of sulfur and VGCF has been ball-milled up to $10 \mathrm{~h}$, the obtained precursor also has a burr-like shape as shown in Fig. 3 (c). The morphology of the 10 h-ball-milled precursors is almost same as that of the $5 \mathrm{~h}$-ball-milled precursors. On the other hand, the precursor ball-milled for $70 \mathrm{~h}$ shows a different morphology from the $5 \mathrm{~h}$-and/or 10 h-ball-milled precursors. The surface of the 70 h-ball-milled precursor is somewhat smooth in comparison with the 5 h-and/or 10 h-ball-milled precursors. The particle size of the 70 h-ball-milled precursor is about $15 \mu \mathrm{m}$ and becomes in some degree larger than that of the $5 \mathrm{~h}$-and/or $10 \mathrm{~h}$-ball-milled precursors. Those results suggest that an aggregation of the particles occurred during the long time. The VGCF fibers are braked down and the length of the fibers becomes shorter during the ball-milling process. We suppose that the morphology change of VGCF would be related to the aggregation of the precursors. Then, the precursor ball-milled for $10 \mathrm{~h}$ in Step-A has the smallest particle size among the precursors obtained with various milling times.

The sulfur-VGCF-solid electrolytes composites are prepared from the mixture of the precursors and the solid electrolytes, $\mathrm{a}-\mathrm{Li}_{3} \mathrm{PS}_{4}$, by the ball-milling process (Step-B). Fig. 4 shows the XRD spectra of the sulfur-VGCF-SE composites (S : VGCF : a-Li ${ }_{3} \mathrm{PS}_{4}$ $=30: 10: 60$ in wt. \%) that have prepared by the Step-B with various ball-milling times. In the Step-B, the precursor that has ball-milled for $10 \mathrm{~h}$ in the Step-A is used as raw materials. The XRD spectra of the precursor that has been obtained by the ball-milling (Step-A) for $10 \mathrm{~h}$, and of the amorphous $\mathrm{Li}_{3} \mathrm{PS}_{4}$ solid electrolytes are also shown as Fig. 4 (a) and (b), respectively, for comparison. In the XRD spectrum of the precursor that has been obtained by the Step-A, the diffraction lines of sulfur crystal are observed as shown in Fig. 4 (a). The $\mathrm{Li}_{3} \mathrm{PS}_{4}$ solid electrolyte shows a halo pattern in the XRD spectrum as shown in Fig. 4 (b), thus the electrolyte is in amorphous state. 
The spectrum of the composite mixed by using a pestle and a mortar exhibits the diffraction lines which can be attributed to sulfur crystals as shown in Fig. 4 (c). The XRD spectrum of the composite ball-milled for $3 \mathrm{~h}$ in Step-B is shown as Fig. 4 (d) and the diffraction lines of crystalline sulfur are slightly observed in the spectrum. The XRD spectra of the composites ball-milled for $5 \mathrm{~h}, 10 \mathrm{~h}$ and $20 \mathrm{~h}$ are respectively shown as Fig. 4 (e), (f) and (g). In those spectra only halo patterns are observed. The results indicate that the sulfur crystalline phase in the composite has been changed into amorphous state by the ball-milling process (Step-B).

\subsection{Electrochemical properties of the sulfur-VGCF-SE composites as positive electrode materials for all-solid-state batteries}

The sulfur-VGCF-SE composites as positive electrode materials have been prepared by use of the two-step ball-milling process: Step-A is milling process of sulfur and VGCF to provide the precursors and Step-B is the milling process of the obtained precursors and the solid electrolytes to give the final sulfur-VGCF-SE composites. First of all we investigated the influence of the milling time in Step-A on the electrochemical properties as positive electrode materials for all-solid-state cells. Composite-A was prepared with various milling times of Step-A and with a constant milling time $5 \mathrm{~h}$ of Step-B.

Fig. 5 shows the first discharge-charge curves of the all-solid-state test cells with the composite-A which has been prepared with the various milling times, $3 \mathrm{~h}, 10 \mathrm{~h}$ and $70 \mathrm{~h}$, in the Step-A. The abscissa of the figure is the capacity calculated on the base of weights of sulfur contained in the positive electrode. The discharge-charge cycling test of the cells has been carried under a constant current density of $0.1 \mathrm{mAcm}^{-2}$. In 
the test, discharge-charge criteria of voltage have been set 0.9 to $2.6 \mathrm{~V}$, respectively. The first discharge and charge capacities of the composite-A with the milling time $3 \mathrm{~h}$ in Step-A are about 580 and $550 \mathrm{mAhg}^{-1}$, respectively, as shown in Fig. 5 (a). The discharge-charge efficiency of the first cycle is about $105 \%$. The discharge-charge curves of the composite-A that has been ball-milled for $10 \mathrm{~h}$ and $70 \mathrm{~h}$ in Step-A are shown in the figure (b) and (c), respectively. The discharge capacities of the cells with composite-A with the milling times $10 \mathrm{~h}$ and $70 \mathrm{~h}$ in Step-A are $650 \mathrm{mAhg}^{-1}$ and $580 \mathrm{mAhg}^{-1}$, respectively. The discharge-charge efficiencies of those test cells are about $105 \%$ and the almost same as that of the $3 \mathrm{~h}$-ball-milled composite-A. Indeed, the composite-A with the milling time $10 \mathrm{~h}$ shows a discharge capacity larger than that of the other composites. The discharge-charge characteristics of the composite-A with various milling times in Step-A are, however, very similar and the capacities of those composites are practically same. The discharge capacities of the composite-A with the different milling times in Step-A are about $35 \sim 39 \%$ of the theoretical capacity of sulfur $\left(1675 \mathrm{mAhg}^{-1}\right)$. Those results suggest that the milling time in Step-A scarcely affects on the discharge-charge properties of the test cells.

In order to investigate the influence of the milling time in Step-B on the discharge property of the sulfur-VGCF-SE composites, composite-B was prepared with the constant milling time of $10 \mathrm{~h}$ in Step-A and the various milling times in Step-B.

Fig. 6 shows the first discharge-charge curves of the test cells with composite-B, which has been obtained with the various milling times, $3 \mathrm{~h}, 20 \mathrm{~h}$ and $40 \mathrm{~h}$, in Step-B. The first discharge capacity of the composite-B ball-milled for $3 \mathrm{~h}$ in Step-B is about $460 \mathrm{mAhg}^{-1}$. On the other hand, the composite-B ball-milled for $20 \mathrm{~h}$ and for $40 \mathrm{~h}$ show large discharge capacities of 1333 and $1310 \mathrm{mAhg}^{-1}$, respectively. Those 
discharge capacities of the composite-B ball-milled for $20 \mathrm{~h}$ and/or $40 \mathrm{~h}$ are two to three times larger than that of the composite ball-milled for $3 \mathrm{~h}$. The discharge capacity of the composites ball milled longer than $20 \mathrm{~h}$ is about $80 \%$ of the theoretical capacity of sulfur. The results suggest that the ball-milling time in Step-B significantly affects on the discharge capacity of the composite-B as positive electrode materials in all-solid-state batteries.

The relation between the first discharge capacity and the milling time in Step-B is shown in Fig. 7. The discharge capacity is increased with an increase in the milling time of Step-B in the range of 0 to $20 \mathrm{~h}$, and reaches the saturation with the milling time longer than $20 \mathrm{~h}$. The saturated capacity is about $1300 \mathrm{mAhg}^{-1}$. The result suggests that the discharge properties of the sulfur-VGCF-SE composites are remarkably affected with the milling time of Step-B. All the composites that have been ball-milled longer than $5 \mathrm{~h}$ in Step-B are in amorphous states. Thus, we suppose that there is no relation between the amounts of amorphous sulfur and the capacities of the cells.

The Step-B is the ball-milling process of the solid electrolyte and the precursor that is the mixture of sulfur and VGCF. The contact between the solid electrolyte and the sulfur should be improved by the ball-milling process Step-B. In the all-solid-state battery, electrochemical reactions progress through the solid-solid interface between the solid electrolytes and the electrode materials. Thus, adequate contacts between the solid electrolytes and the electrode materials are necessary to achieve good charge-discharge performance of the battery. The composites-B that has been ball-milled more than $20 \mathrm{~h}$ in Step-B shows good electrochemical performance as positive materials for all-solid-state batteries. 
Fig. 8 shows the discharge-charge cycle behavior of the all-solid-state cell with the composite-B that has been prepared with the milling time of $10 \mathrm{~h}$ for Step-A and the time of $40 \mathrm{~h}$ for Step-B. The discharge-charge cycling test has been carried out under a constant current density of $0.1 \mathrm{mAcm}^{-2}$ and the cut-off voltages of 2.6 to $1.0 \mathrm{~V}$ at $25{ }^{\circ} \mathrm{C}$. At the first cycle, the discharge capacity is $1320 \mathrm{mAhg}^{-1}$ and the charge capacity is $1270 \mathrm{mAhg}^{-1}$. The coulombic efficiency of the first cycle is about $104 \%$. After the second cycle, the test cell shows the almost same discharge-charge capacity more than $1200 \mathrm{mAhg}^{-1}$ and the coulombic efficiency is almost unity. The test cell kept the long plateau at about $1.5 \mathrm{~V}$ even after 50 cycles.

The cycle dependence of the discharge capacity and the coulombic efficiency of the all-solid-state cell are shown in Fig. 9. The test cell is assembled with the composite-B that has been ball-milled for $10 \mathrm{~h}$ in Step-A, and for $40 \mathrm{~h}$ in Step-B. The test cell shows the first discharge capacity more the $1320 \mathrm{mAhg}^{-1}$ and keeps the capacity more than $1200 \mathrm{mAhg}^{-1}$ even after 50 cycles. This capacity after 50 cycles is more than $90 \%$ of the initial discharge capacity. Lithium-sulfur batteries with conventional liquid electrolytes have been reported to show rapid capacity fading upon discharge-charge cycling. This rapid fading of the capacity of $\mathrm{Li} / \mathrm{S}$ batteries is attributed to the dissolution of poly-sulfide ions into the electrolyte solutions. The all-solid-state battery with the inorganic solid electrolyte, a- $\mathrm{Li}_{3} \mathrm{PS}_{4}$, is hardly degrades on the electrochemical performance during the discharge-charge cycling. Those results suggest that the all-solid-state lithium-sulfur battery is very attractive as a power source to have large specific capacity and good discharge-charge cycle ability.

\section{Conclusions}


The sulfur-carbon composites were prepared by the two-step ball milling process: The first step (Step-A) was ball milling process for mixing sulfur and carbon material (VGCF) and gave a precursor. The other step (Step-B) was a process for mixing the precursor and the solid electrolyte $\left(\mathrm{SE}, \mathrm{a}-\mathrm{Li}_{3} \mathrm{PS}_{4}\right)$ and gave the composites as positive electrode materials for all-solid-state batteries. Laboratory-scale solid-state cells were constructed with the sulfur-VGCF-SE composites as cathode materials. The amorphous $\mathrm{Li}_{3} \mathrm{PS}_{4}$ and the meta-stable $\mathrm{Li}_{4.4} \mathrm{Si}$ alloy were used as solid electrolytes and anode materials for the test cells. The milling time of Step-A scarcely influenced of the discharge capacity of the composites. On the other hand, the discharge capacity of the composites was remarkably affected by the milling time of Step-B. The capacity was increased with an increase in the milling time of Step-B and reached the saturation with the milling time longer than $20 \mathrm{~h}$. The composite obtained with the milling time $10 \mathrm{~h}$ of Step-A and with the milling time $20 \mathrm{~h}$ of Step-B showed a large specific capacity more than $1300 \mathrm{mAhg}^{-1}$ and kept the capacity larger than $1200 \mathrm{mAhg}^{-1}$ even after 50 discharge-charge cycles. The contact between the solid electrolyte and the sulfur should be improved by the ball-milling process Step-B. Those results suggest that the adequate contacts between the solid electrolytes and sulfur are necessary to achieve good discharge-charge performance of the all-solid-state batteries.

\section{Acknowledgements}

This work was partly supported by Japan Science and Technology Agency and by the Grand-in-Aid for Scientific Research, from the Ministry of Education, Culture, Sports and Technology of Japan. 


\section{Reference:}

[1] C. Daniel and J. O. Besenhard eds., "Handbook of Battery Materials 2nd," Wiley-VCH Verlag \& KGaA, Germany (2012).

[2] H. S. Kim, C. -S. Jeong, and Y. -T. Kim, J. Appl. Electrochem., $\underline{42}$ (2012) 75.

[3] W. Wang, Y. Wang, Y. Huang, C. Huang, Z. Yu, H. Zhang, A. Wang, and K. Yuan, J. Appl. Electrochem., $\underline{\mathbf{4 0}}$ (2010) 321.

[4] Y. Yang, G. Zheng, S. Misra, J. Nelson, M. F. Toney, and Y. Cui, J. Am. Chem. Soc., $\underline{134}$ (2012) 15387.

[5] J. Shim, K. A. Striebel, and E. J. Cairns, J. Electrochem. Soc., 149 (2002) A1321.

[6] S. E. Choen, J. H. Cho, K. S. Ko, C. W. Kwon, D. R. Chang, H. T. Kim, and S. K. Kim, J. Electrochem. Soc., 149 (2002) A1437.

[7] D. Marmorstein, H. Yu, K. A. Striebel, F. R. McLarnon, J. Hou, and E. J. Cairns, J. Power Sources, $\underline{\mathbf{8 9}}$ (2000) 219.

[8] E. Levillain, F. Gaillard, and J. P. Lelieur, J. Electroanal. Chem., $\underline{432}$ (1997) 129.

[9] E. Peled, Y. Sternberg, A. Gorenshtein, and J. Lavi, J. Electrochem. Soc., 136 (1989) 1621.

[10] H. Yamin, A. Gorenshtein, J. Pencier, Y. Sternberg, and E. Peled, J. Electrochem. Soc., $\underline{135}$ (1988) 1045.

[11] J. Paris and V. Plichon, Electrochim. Acta, 26 (1981) 1823.

[12] N. Machida and T. Shigematsu, Chem. Lett., $\underline{\mathbf{3 3}}$ (2004) 376.

[13] N. Machida, K. Kobayashi, Y. Nishikawa, and T. Shigematsu, Solid State Ionics, $\underline{175}$ (2004) 247. 
[14] M. Nagao, Y. Imade, H. Narisawa, T. Kobayashi, R. Watanabe, T. Yokoi, T. Tatsumi, and R. Kanno, J. Power Sources, $\underline{222}$ (2013) 237.

[15] M. Nagao, A. Hayashi, and M. Tatsumisago, Electrochem. Comm., 22 (2012) 177.

[16] A. Hayashi, T. Ohtomo, F. Mizuno, K. Tadanaga, and M. Tatsumisago, Electrochem. Comm., $\underline{\mathbf{5}}$ (2003) 701.

[17] T Takeuchi, H. Kageyama, K. Nakanishi, M. Tabuchi, H. Sakaeda, T. Ohta, H. Senoh, T. Sakai, and K. Tatsumi, J. Electrochem. Soc., 157 (2010) A1196.

[18] T. Takeuchi, H. Sakaeda, H. Kageyama, H. Senoh, T. Sakai, and K. Tatsumi, J. Power Sources, $\underline{195}$ (2010) 2928.

[19] T. Kobayashi, Y. Imade, D. Shishihara, K. Homma, M. Nagao, R. Watanabe, T. Yokoi, A. Yamada, R. Kanno, and T. Tatsumi, J. Power Sources, $\underline{182}$ (2008) 621.

[20] M. Nagao, A. Hayashi, and M. Tatsumisago, Electrochim. Acta, $\underline{\mathbf{5 6}}$ (2011) 6055.

[21] A. Hayashi, H. Hama, H. Morimoto, M. Tatsumisago, and T. Minami, J. Am. Ceram. Soc., $\underline{84}$ (2001) 477.

[22] A. Hayashi, S. Hama, T. Minami, and M. Tatsumisago, Electrochem. Comm., $\underline{\mathbf{5}}$ (2003) 111.

[23] N. Machida, H. Yamamoto, and T. Shigematsu, Chem. Lett., $\underline{\mathbf{3 3}}$ (2004) 30.

[24] N. Machida, H. Yamamoto, S. Asano, and T. Shigematsu, Solid State Ionics, $17 \mathbf{6}$ (2005) 473.

[25] Y. Hashimoto, N. Machida, and T. Shigematsu, Solid State Ionics, 175 (2004) 177. 
[26] R. Tamori, N. Machida, and T. Shigematsu, J. Jpn. Soc. Powder and Powder Metallurgy, $\underline{48}$ (2001) 267.

\section{Figure Captions:}

Fig. 1 Schematic diagram of preparation process of sulfur-VGCF composites.

Fig. 2 XRD patterns of the precursors ball-milled for various times; (a) MM $5 \mathrm{~h}$, (b) 
MM 10 h, (c) MM 20 h, (d) MM 40 h, and (e) MM 70h.

Fig. 3 SEM images of (a) VGCF and precursors obtained by Step-A with various milling times; (b) MM 5 h, (c) MM 10 h, and (d) MM $70 \mathrm{~h}$.

Fig. 4 The XRD patterns of the sulfur-VGCF-solid electrolyte composites obtained by Step-B with the various-milling times; (c) $0 \mathrm{~h}$, (d) $3 \mathrm{~h}$, (e) $5 \mathrm{~h}$, (f) $10 \mathrm{~h}$ and (g) $20 \mathrm{~h}$. The XRD patterns of (a) the precursor prepared by Step-A with a milling time of $10 \mathrm{~h}$ and of (b) solid electrolyte (amorphous $\mathrm{Li}_{3} \mathrm{PS}_{4}$ ) are also shown in the figure for composition.

Fig. 5 The first discharge-charge cycle curves of the all-solid-state cell with the composite-A that were prepared with the various milling times; (a) $3 \mathrm{~h}$, (b) $10 \mathrm{~h}$ and (c) $70 \mathrm{~h}$ in the Step-A. (See the text in detail.)

Fig. 6 The first discharge-charge cycle curves of the all-solid-state cells with the composite-B that were prepared with the various milling times; (a) $3 \mathrm{~h}$, (b) $20 \mathrm{~h}$ and (c) $40 \mathrm{~h}$ in the Step-B. (See the text in detail.)

Fig. 7 The relation between the first discharge capacity and the milling time in Step-B of the composite-B. 
Fig. 8 The discharge-charge cycle curves of the all-solid-state cells with the composite-B that was prepared with the milling time of $10 \mathrm{~h}$ for the Step-A and the time of $40 \mathrm{~h}$ for the Step-B.

Fig. 9 The cycle dependences of the discharge capacity and the coulombic efficiency of the all-solid-state cell with the composite-B that was prepared with the milling time of $10 \mathrm{~h}$ for the Step-A and the time of $40 \mathrm{~h}$ for the Step-B. The discharge-charge cycle test was carried out under a constant current density of $0.1 \mathrm{mAcm}^{-2}$ with the cut-off voltage range of 2.6 to $1.0 \mathrm{~V}$. 


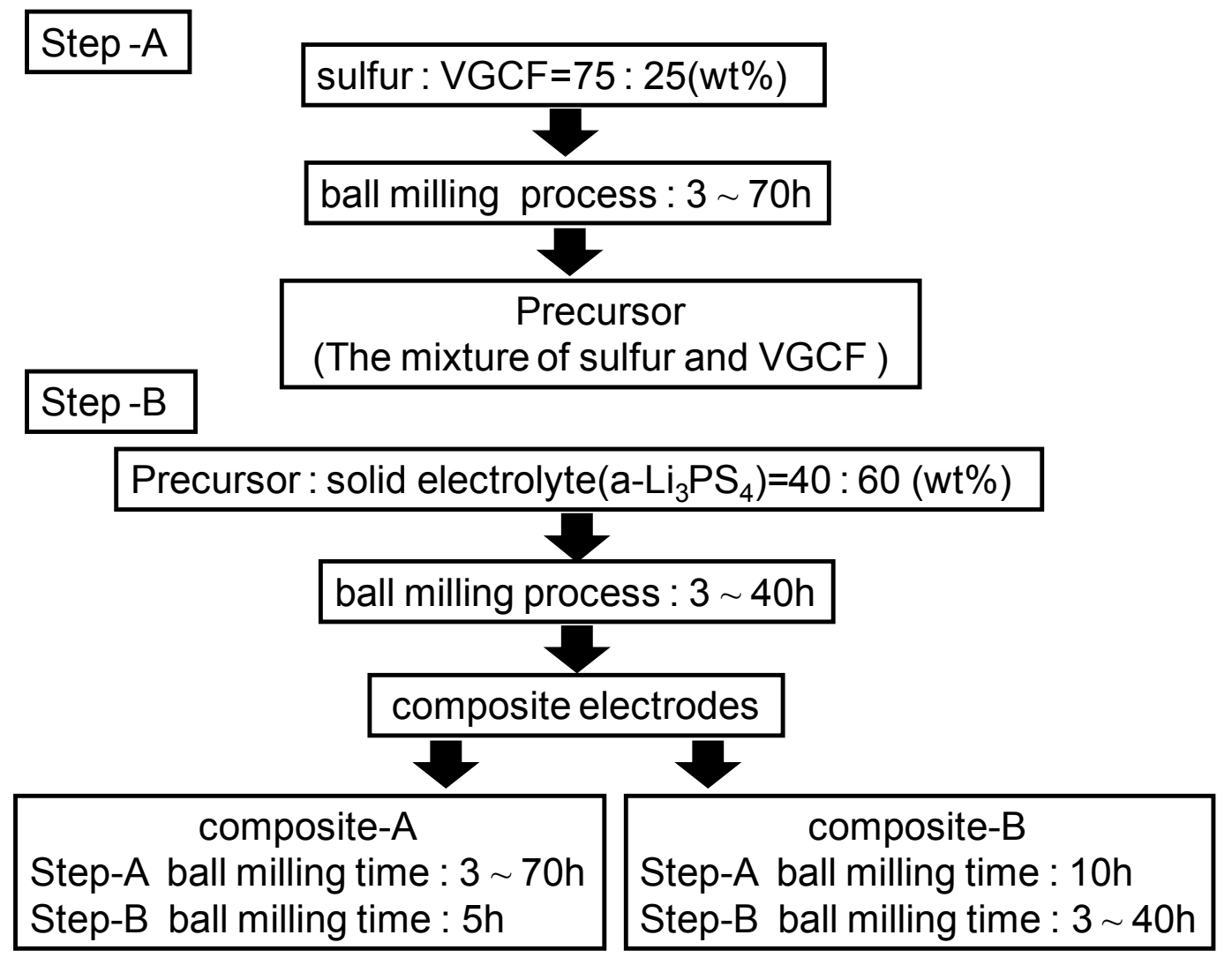

Fig. 1 S. Kinoshita et. al. 


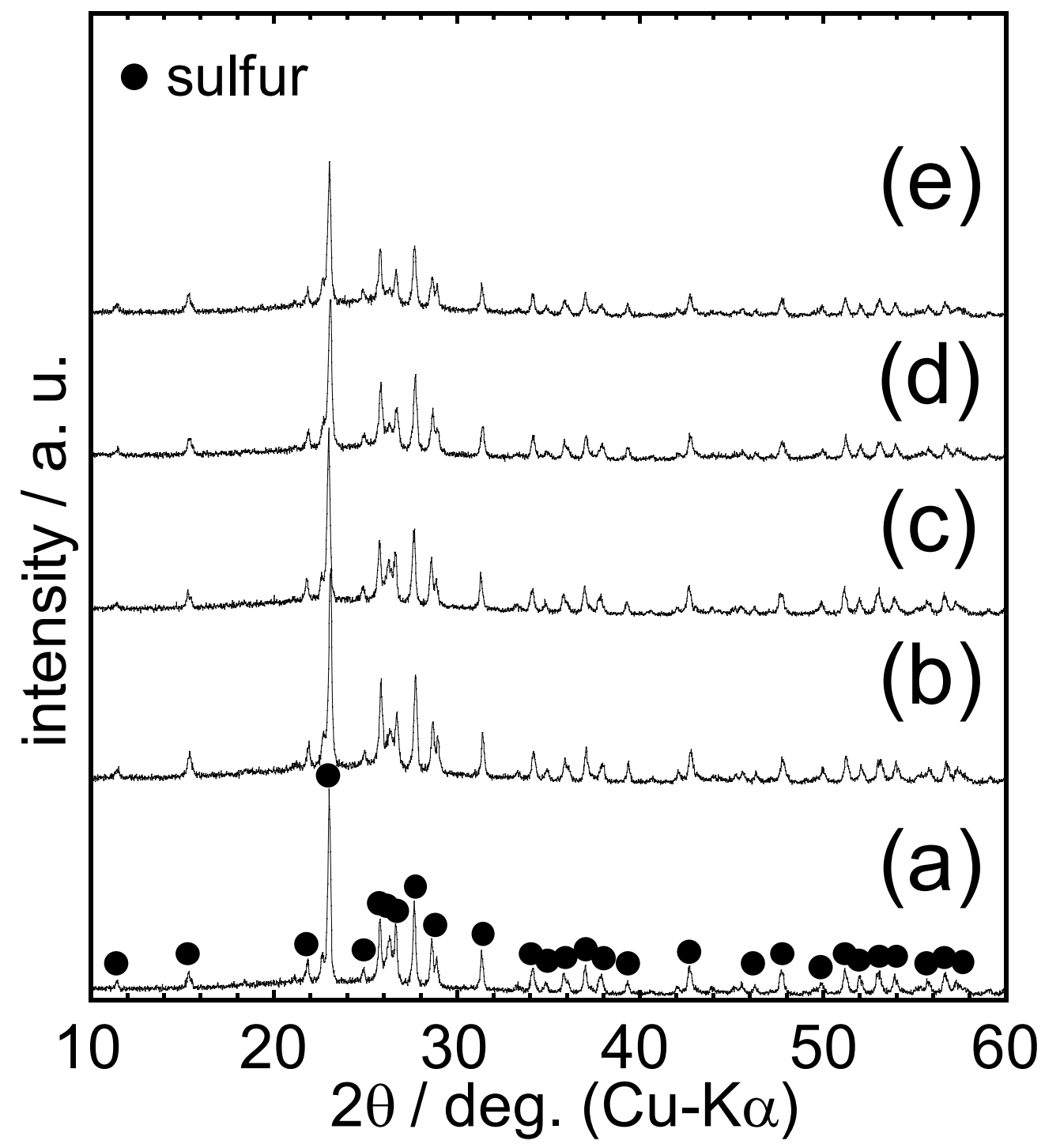

Fig. 2 S. Kinoshita et. al. 

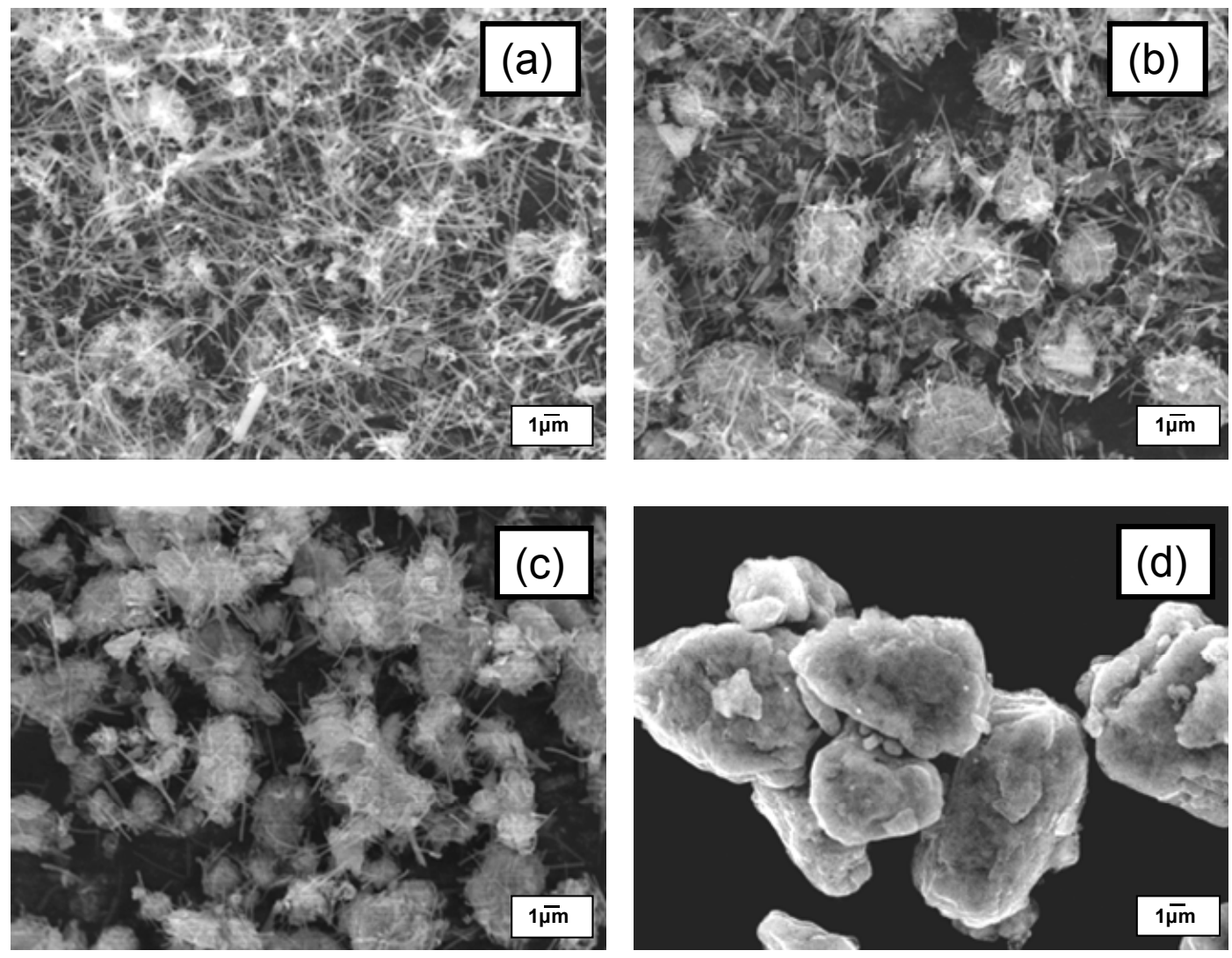

Fig. 3 S. Kinoshita et. al. 


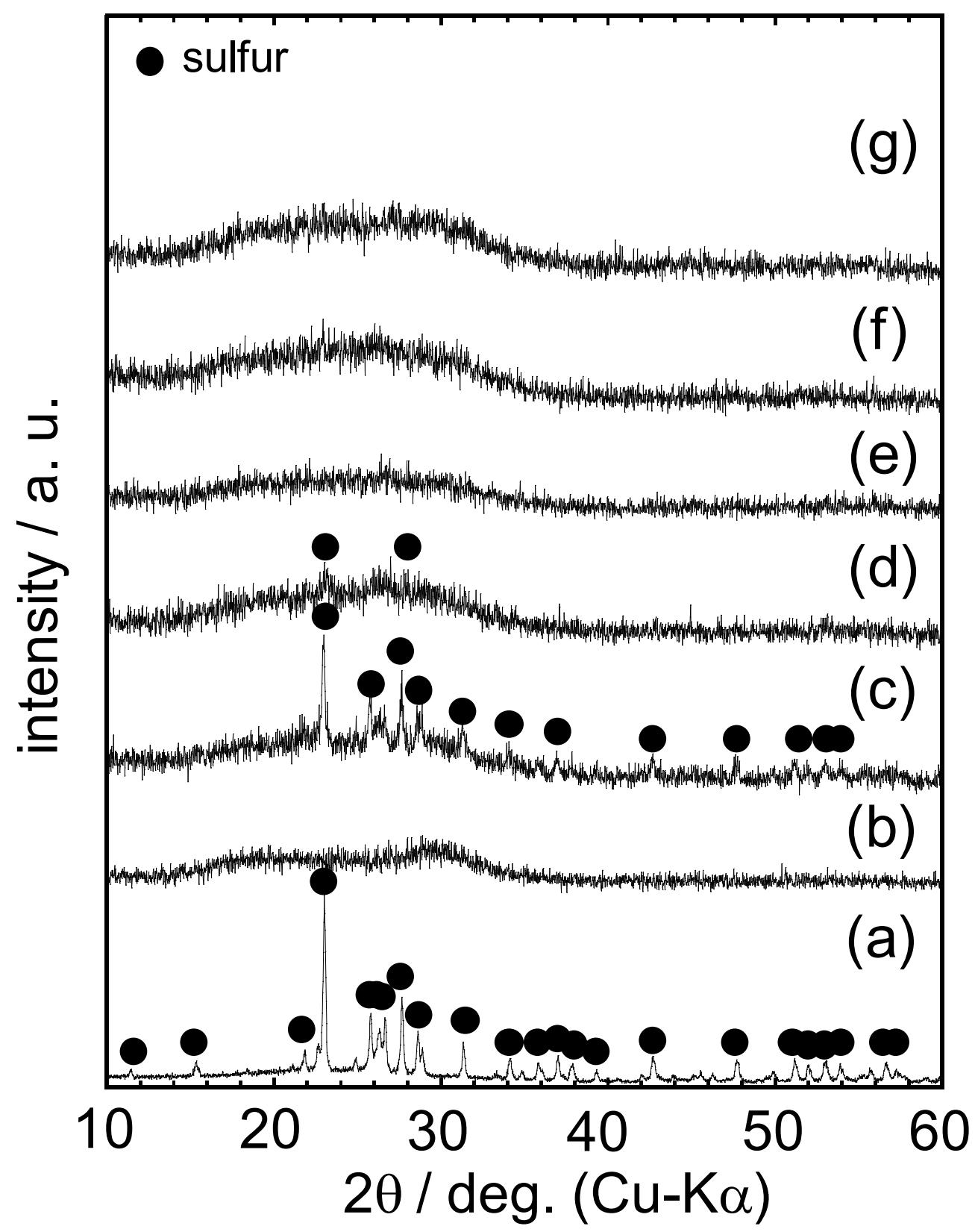

Fig. 4 S. Kinoshita et. al. 


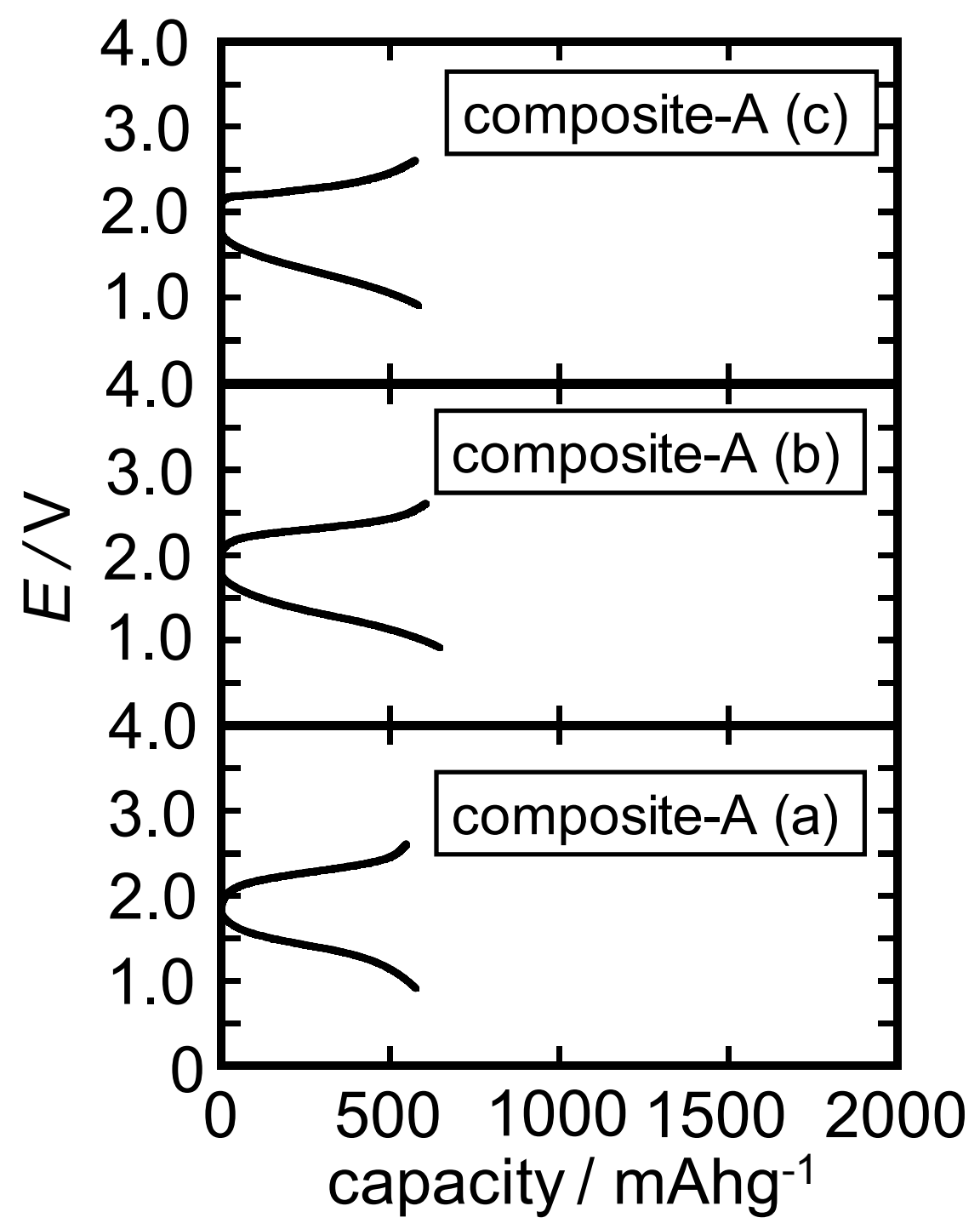

Fig. 5 S. Kinoshita et. al. 


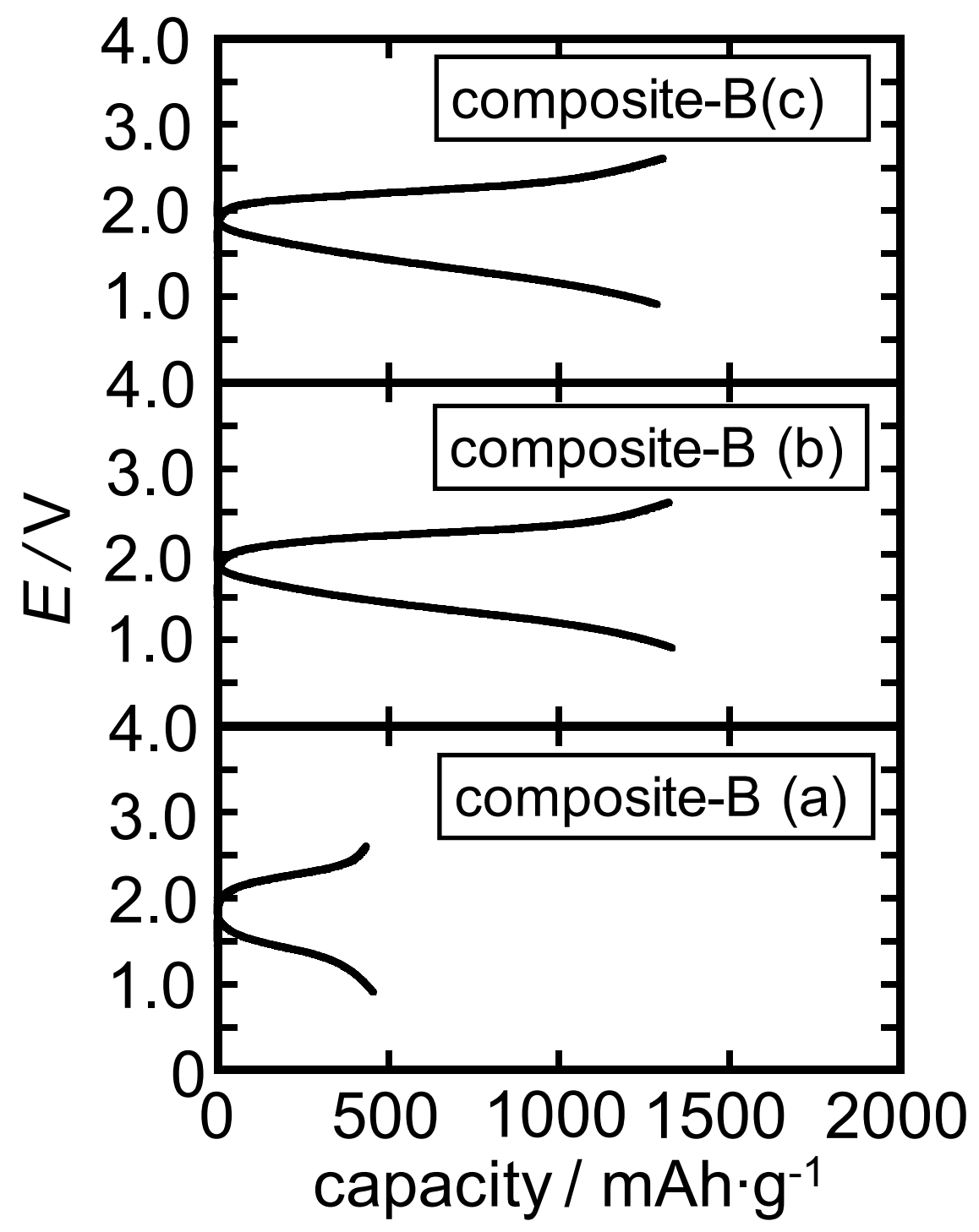

Fig. 6 S. Kinoshita et. al. 


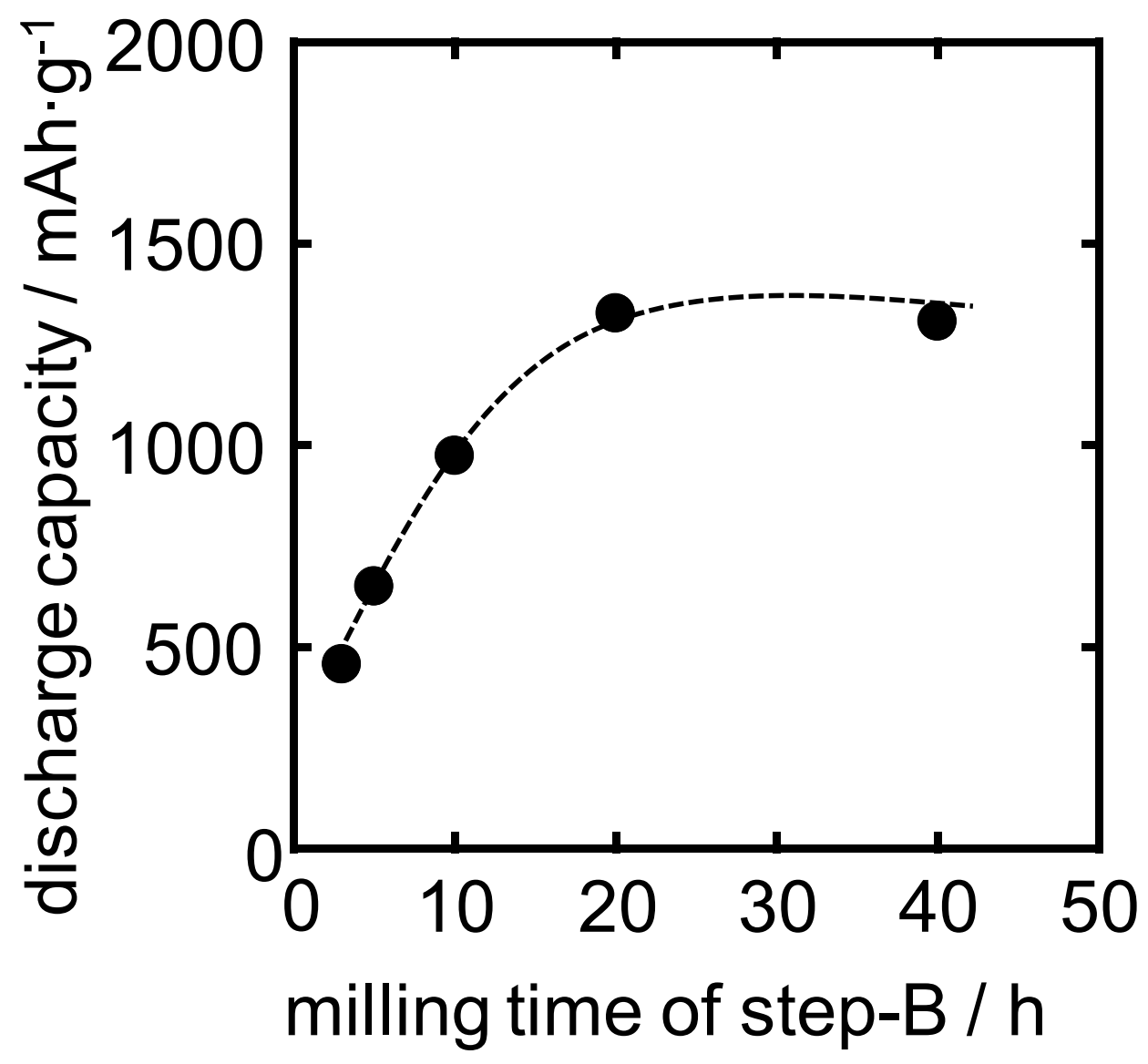

Fig. 7 S. Kinoshita et. al. 


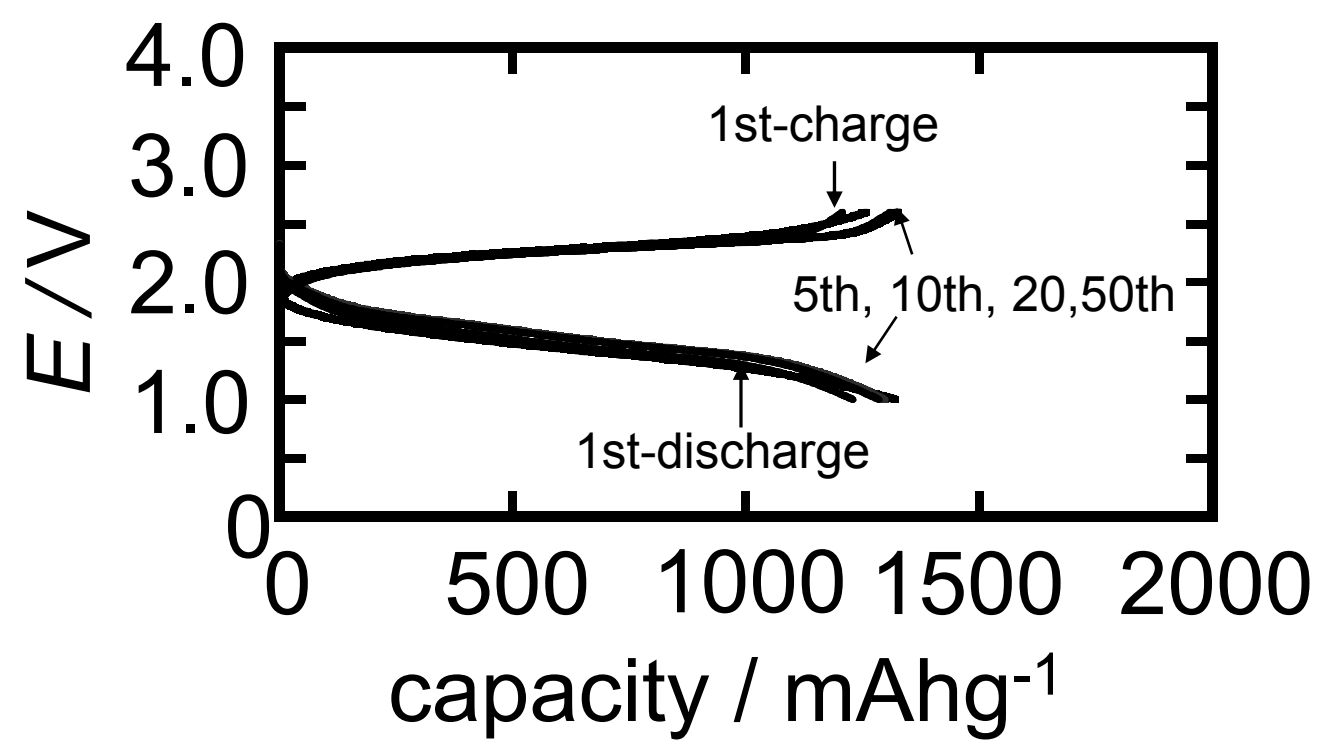

Fig. 8 S. Kinoshita et. al. 


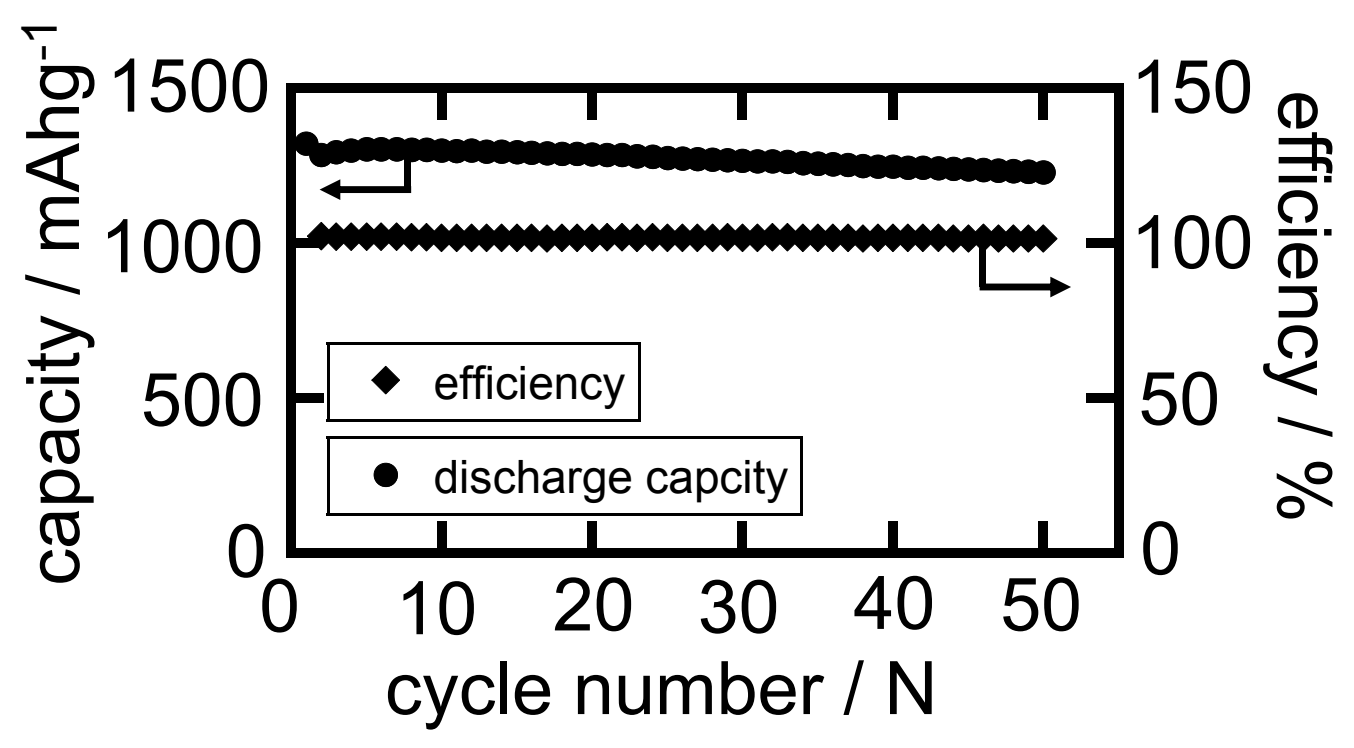

Fig. 9 S. Kinoshita et. al. 